\title{
Thyrotoxicosis in Graves' Disease with Invasive Laryngeal Cancer
}

\author{
Hiroshi Nomoto ${ }^{1,2}$ and Mayuko Oita ${ }^{1,3}$
}

Key words: Graves' disease, invasive laryngeal cancer, thyrotoxicosis

(Intern Med 57: 1495-1496, 2018)

(DOI: 10.2169/internalmedicine.9644-17)

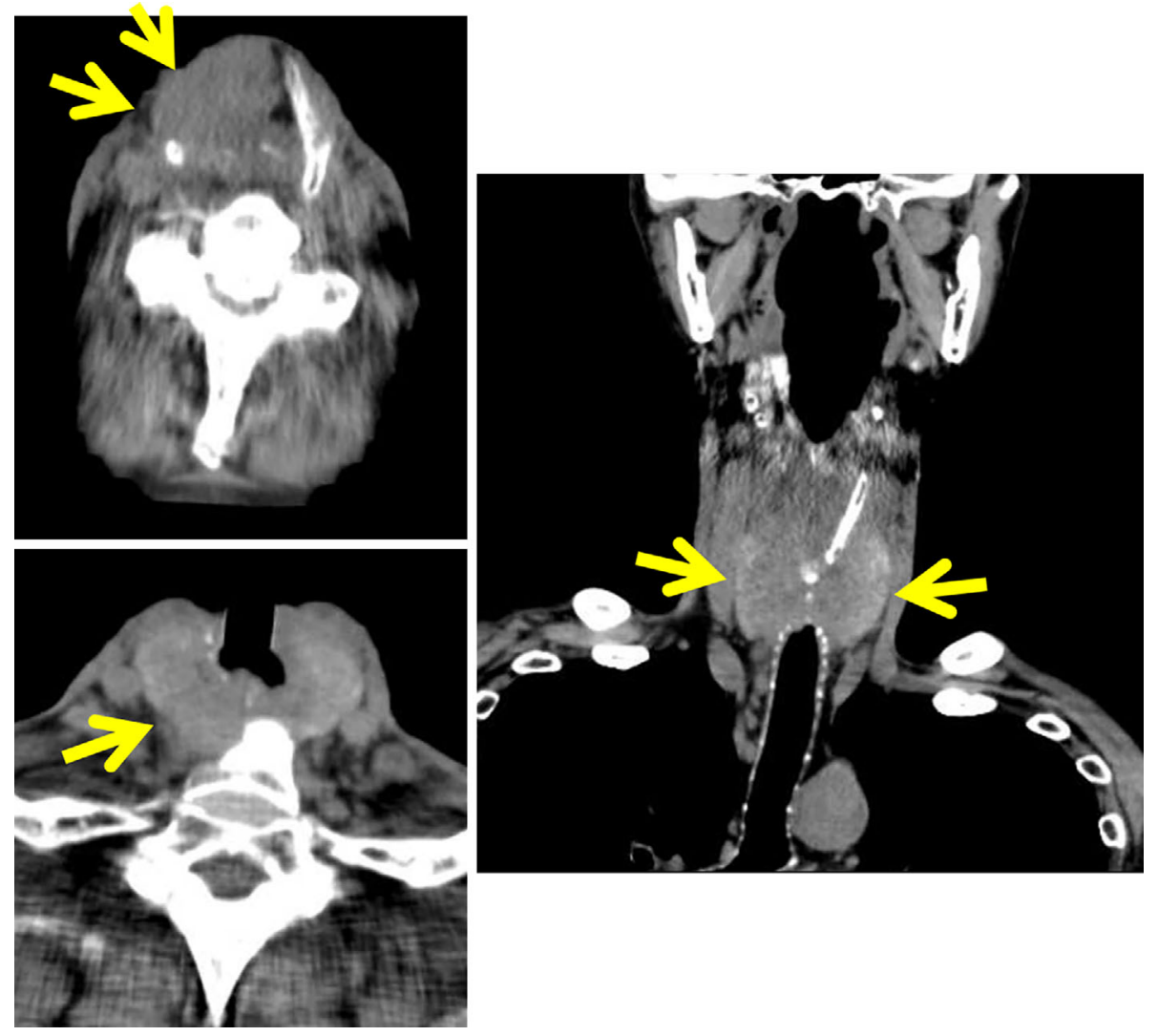

Picture 1.

A 53-year-old man diagnosed with advanced laryngeal cancer treated with radiotherapy was admitted to our facility because of general malaise and tachycardia. The thyroid gland was enlarged with induration; cervical computed tomography and sonography revealed that most of the thyroid gland had been replaced by invasive laryngeal carcinoma (Picture 1, 2). Laboratory data showed thyrotoxicosis (TSH
$<0.05 \mu \mathrm{U} / \mathrm{mL}$, free $\mathrm{T} 312.72 \mathrm{pg} / \mathrm{mL}$, free $\mathrm{T} 46.79 \mathrm{ng} / \mathrm{dL}$ ) and high-titer TSH receptor antibody (7.6 IU/L). Such findings hampered distinguishing Graves' disease from destructive thyroiditis associated with invasive or metastatic cancer (1). Furthermore, TSH receptor antibody can be detected even after destructive thyroiditis (2). Technetium-99m pertechnetate scintigraphy was performed (Picture 3), and

\footnotetext{
${ }^{1}$ Department of Internal Medicine, Tomakomai City Hospital, Japan, ${ }^{2}$ Department of Rheumatology, Endocrinology and Nephrology, Faculty of Medicine and Graduate School of Medicine, Hokkaido University, Japan and ${ }^{3}$ Department of Medicine and Division of Diabetes and Endocrinology, Sapporo Medical Center, NTT East Corporation, Japan

Received: June 9, 2017; Accepted: September 20, 2017; Advance Publication by J-STAGE: December 27, 2017

Correspondence to Dr. Hiroshi Nomoto, hnomoto@med.hokudai.ac.jp
} 

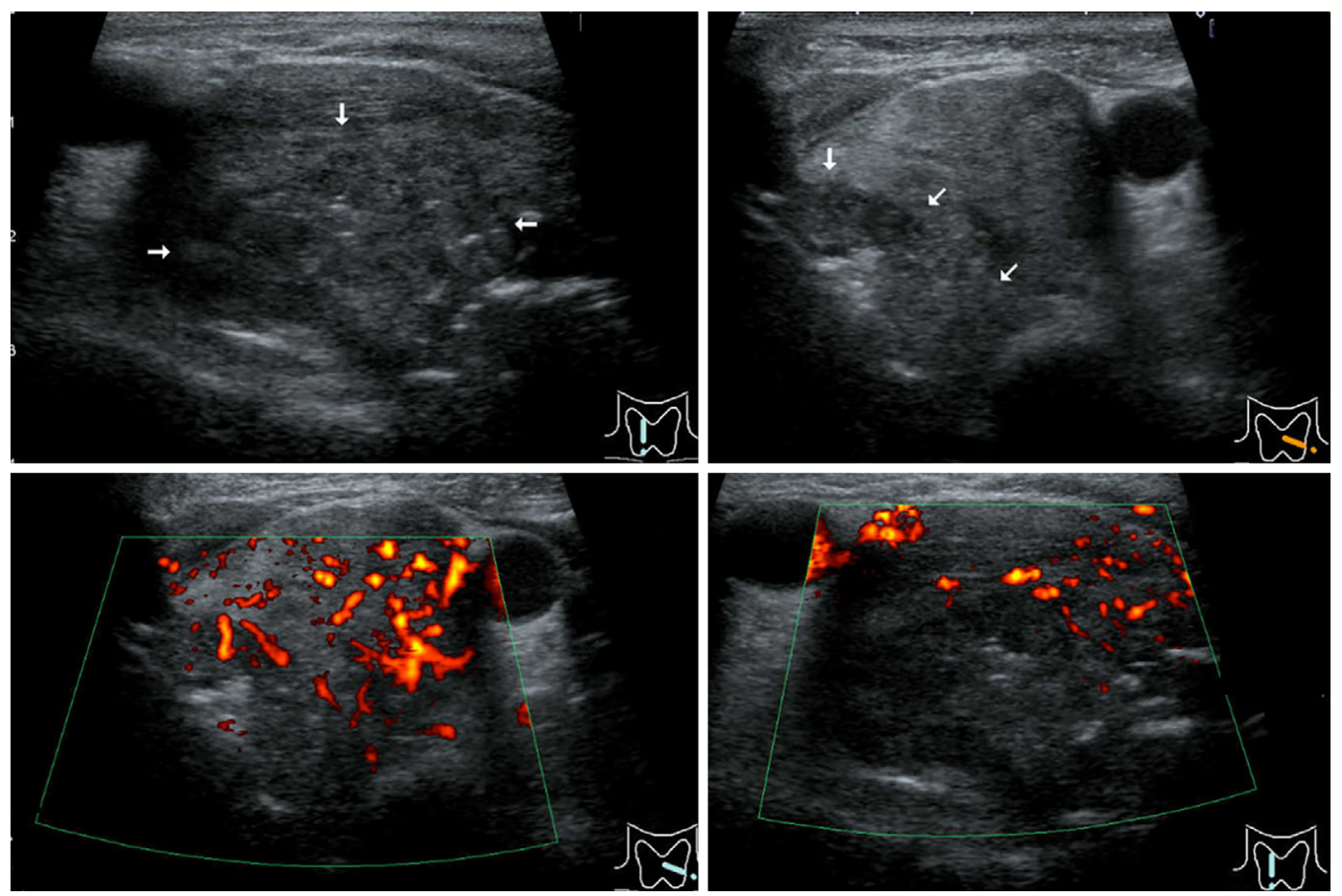

Picture 2.

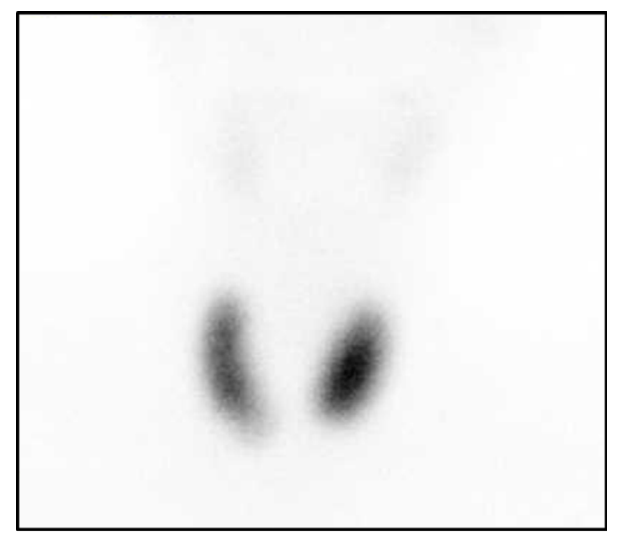

Total Uptake: $6.3 \%$

Picture 3.

we ultimately diagnosed thyrotoxicosis in Graves' disease. We therefore propose that the radioactive iodine uptake be carefully measured in order to distinguish between Graves' disease and destructive hyperthyroidism in cases of thyrotoxicosis with invasion of carcinoma involving the thyroid gland.

The authors state that they have no Conflict of Interest (COI).

\section{References}

1. Eriksson M, Ajmani SK, Mallette LE. Hyperthyroidism from thyroid metastasis of pancreatic adenocarcinoma. JAMA 238: 12761278, 1977.

2. Fukata S, Matsuzuka F, Kobayashi A, Hirai K, Kuma K, Sugawara M. Development of Graves' disease after subacute thyroiditis: two unusual cases. Acta Endocrinol (Copenh) 126: 495-496, 1992.

The Internal Medicine is an Open Access article distributed under the Creative Commons Attribution-NonCommercial-NoDerivatives 4.0 International License. To view the details of this license, please visit (https://creativecommons.org/licenses/ by-nc-nd/4.0/).

\footnotetext{
(C) 2018 The Japanese Society of Internal Medicine Intern Med 57: 1495-1496, 2018
} 